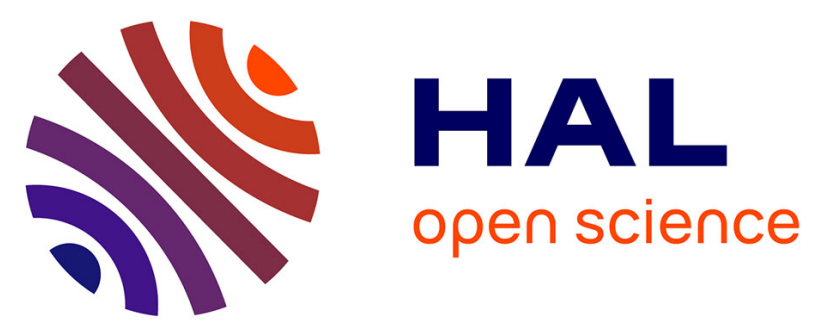

\title{
Parameters influencing ciprofloxacin, ofloxacin, amoxicillin and sulfamethoxazole retention by natural and converted calcium phosphates
}

H Bouyarmane, I. El Hanbali, M. El Karbane, A Rami, A Saoiabi, S Saoiabi, Sylvie Masse, T. Coradin, A Laghzizil

\section{To cite this version:}

H Bouyarmane, I. El Hanbali, M. El Karbane, A Rami, A Saoiabi, et al.. Parameters influencing ciprofloxacin, ofloxacin, amoxicillin and sulfamethoxazole retention by natural and converted calcium phosphates. Journal of Hazardous Materials, 2015, 291, pp.38-44. 10.1016/j.jhazmat.2015.02.049 . hal-01120277

\section{HAL Id: hal-01120277 \\ https://hal.sorbonne-universite.fr/hal-01120277}

Submitted on 25 Feb 2015

HAL is a multi-disciplinary open access archive for the deposit and dissemination of scientific research documents, whether they are published or not. The documents may come from teaching and research institutions in France or abroad, or from public or private research centers.
L'archive ouverte pluridisciplinaire HAL, est destinée au dépôt et à la diffusion de documents scientifiques de niveau recherche, publiés ou non, émanant des établissements d'enseignement et de recherche français ou étrangers, des laboratoires publics ou privés. 


\section{Parameters influencing ciprofloxacin, ofloxacin, amoxicillin and}

\section{sulfamethoxazole retention by natural and converted calcium}

\section{phosphates}

H. Bouyarmane ${ }^{\text {a }}$, I. El Hanbali, ${ }^{\text {ab,c }}{ }^{\text {M. }}$ El Karbane, ${ }^{\text {d }}$ A. Rami, ${ }^{\text {d }}$ A. Saoiabi, ${ }^{\text {a }}$ S. Saoiabi, ${ }^{a}$

S. Masse ${ }^{\mathrm{b}, \mathrm{c}}$, T. Coradin ${ }^{\mathrm{b}, \mathrm{c}, *}$ and A. Laghzizil ${ }^{\mathrm{a}, *}$

${ }^{a}$ Laboratoire de Chimie Physique Générale, Université Mohammed V-Agdal, Faculté des Sciences BP.1014 Rabat, Morocco

${ }^{\mathrm{b}}$ Sorbonne Universités, UPMC Univ Paris 06, UMR 7574, Laboratoire de Chimie de la Matière Condensée de Paris, F-75005 Paris, France

${ }^{\circ}$ CNRS, UMR 7574, Laboratoire de Chimie de la Matière Condensée de Paris, F-75005 Paris, France

${ }^{d}$ Laboratoire National de Contrôle des Médicaments, Rabat, Morocco

"Corresponding authors:

T. Coradin, Laboratoire de Chimie de la Matière Condensée de Paris, Collège de France, 11 place Marcelin Berthelot, F-75005 Paris, France Tel:33-1-44-27-55-17, Fax: 33-1-44-27-47-69, Email address: thibaud.coradin@upmc.fr

A. Laghzizil, Laboratoire de Chimie Physique Générale, Université Mohamed V, Faculté des Sciences BP.1014 Rabat, Morocco, Email address: laghzizi@fsr.ac.ma 


\begin{abstract}
The retention of four antibiotics, ciprofloxacin, ofloxacin, amoxicillin and sulfamethoxazole by a natural phosphate rock (francolite) was studied and compared with a converted hydroxyapatite powder. The maximum sorption capacities were found to correlate with the molecular weight of the molecules. The mechanisms of sorption depended mostly on the charge of the antibiotic whereas the kinetics of the process was sensitive to their hydrophobic/hydrophilic character. The two materials showed slightly distinct affinities for the various antibiotics but exhibited similar maximum sorption capacities despite different specific surface areas. This was mainly attributed to the more pronounced hydrophobic character of the francolite phase constituting the natural phosphate. These data enlighten that the retention properties of these mineral phases depend on a complex interplay between the inter-molecular and molecule-solid interactions. These findings are relevant to understand better the contribution of calcium phosphates in the fate and retention of antibiotics in soils.
\end{abstract}

Keywords: Antibiotics; Phosphates; Retention; Soils

Capsule: The retention of antibiotics by phosphate rocks depends on both intermolecular and molecule-mineral interactions, originating from their charge and hydrophobic characters 


\section{Introduction}

Antibiotics have been used in large quantities for several decades as human and veterinary medicine as well as husbandry growth promoters (Moulin et al., 2008). A part of administered antibiotics is excreted as the parent compound or metabolites via urine and faeces within domestic and hospital wastes (Lin et al., 2008). They are eventually released into soils, sediments and aquatic environments through different pathways and were detected in municipal wastewater, surface water and ground water (Diaz-Cruz, 2003; Kumar et al., 2005; Kümmerer, 2009a)

Many of the antibiotic compounds are hazardous in nature and persist for long time in the environment, as they are poor substrates to indigenous microorganisms (Kümmerer, 2009b). In this context, it is important to evaluate the mechanisms by which they can be retained in soils (Boxall et al., 2002; Thiele-Bruhn, 2003; Chen et al., 2011; Chen et al., 2014; Wegst-Ulrich et al., 2014), including through the study of their interactions with mineral phases (Gao and Pedersen, 2005; G and Karthikeyan, 2005). In parallel, such studies can be of particular relevance to predict the efficiency of mineral amendment for soil remediation purpose (O'Day and Vlassopoulos, 2010 ; Mamindy-Pajany et al., 2013)

Especially, among most common mineral phase used in soil remediation, natural and synthetic calcium phosphates, especially hydroxyapatite derivatives, have been mainly studied for metal remediation (Miretzky and Fernandes-Cirelli, 2008 ; Nzihou and Sharrock, 2010). However, recent reports suggest that calcium phosphates also hold potential for organic pollutant removal (Bahdod et al., 2009; Lin et al., 2009; Bouyarmane et al., 2010). Yet, very little is known about the reactivity of the apatite surface towards complex molecules of environmental relevance. 
In this context, the present study aims at evaluating the retention of four widespread antibiotics, ciprofloxacin, ofloxacin, amoxicillin and sulfamethoxazole by a natural phosphate rock. As a comparison, we used a synthetic porous hydroxyapatite obtained from the natural ore by a dissolution/reprecipitation process. The kinetics and isotherms of sorption were established and modeled in order to clarify the mechanisms of interactions between the antibiotics and the two mineral phases. The influence of $\mathrm{pH}$ on the retention efficiency was studied. The data were discussed in terms of the molecular characteristics (size, charge, hydrophobicity) of the antibiotics and surface properties (porosity, hydrophobicity) of the powders.

\section{Materials and Methods}

\subsection{Chemicals}

Ciprofloxacin (1-cyclopropyl-6-fluoro-4-oxo-7-piperazin-1-yl-quinoline-3-carboxylic acid, CIP), Ofloxacin ((R,S)-9-fluoro-2,3-dihydro-3-methyl-10-(4-methyl-1piperazinyl)-7-oxo-7H-pyrido [1,2,3-de]-1, 4-benzoxazine-6-carboxylic acid, OFL), Amoxicillin $((2 S, 5 R, 6 R)-6-\{[(2 R)-2$-amino-2-(4-hydroxyphenyl)-acetyl $]$ amino $\}-3,3-$ dimethyl-7-oxo-4-thia-1-azabicyclo[3.2.0]heptane-2-carboxylic acid, AMO) and Sulfamethoxazole (4-amino-N-(5-methyl-1,2-oxazol-3-yl)benzenesulfonamide, SUL) were purchased from Aldrich (Fig. 1). Calculated octanol-water partition coefficients $X \log P 3$ were obtained from the PubChem (NCBI) database

(http://pubchem.ncbi.nlm.nih.gov). The Marvin 15.1.12 software (ChemAxon (http://www.chemaxon.com), was used for drawing, displaying and analyzing chemical structures. 

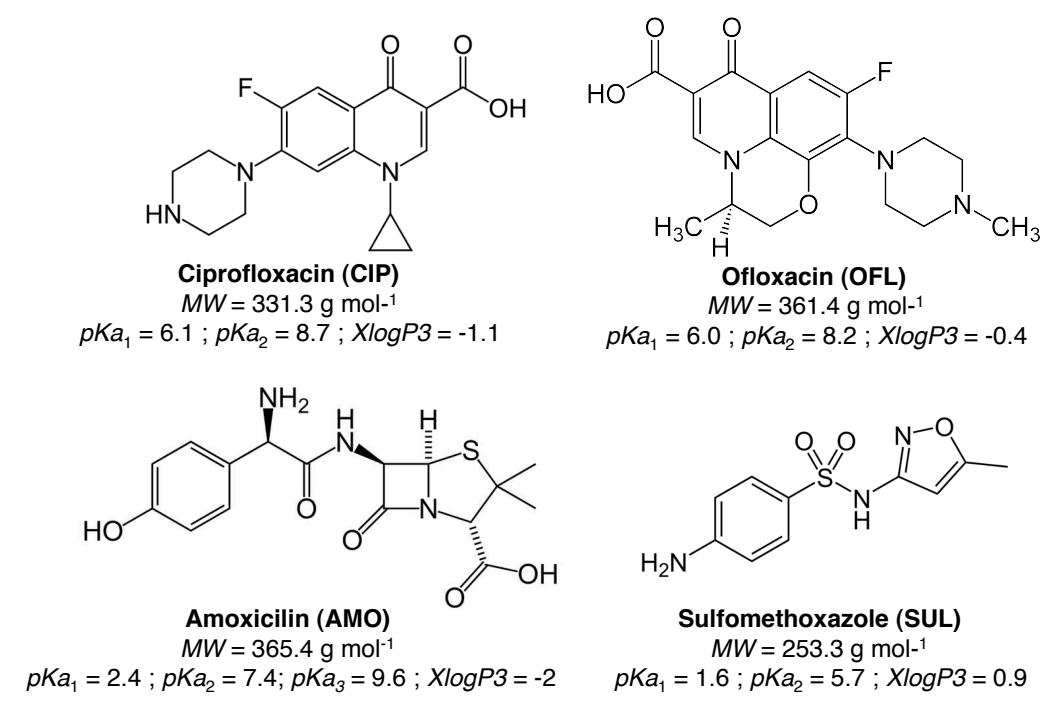

Fig.1 Chemical formula, molecular weights $(M W)$, relevant $p K a$ values and calculated octanol-water partition coefficients $(X \log P 3)$ of antibiotics used in this study

\subsection{Mineral phases}

The natural phosphate (NP) used in this work was from the Bengurir region (Morocco) (El Asri et al., 2009a). The sample was washed and sieved to give a $-400 /+100 \mu \mathrm{m}$ size fraction using ASTM Standard sieves. It consists of francolite, a carbonate-rich form of fluoroapatite together with $c a .2 \mathrm{wt} \% \mathrm{SiO}_{2}$ (quartz). The amount of organic matter is $<$ $1.5 \mathrm{wt} \%$. Its specific surface area is $c a .20 \mathrm{~m}^{2} \mathrm{~g}^{-1}$. The converted porous hydroxyapatite (CP) was obtained from the natural phosphate by a dissolution/reprecipitation method described elsewhere (El Asri et al., 2009b). It consists of a poorly crystalline powder of hydroxyapatite nanoparticles, $c a 50 \mathrm{~nm}$ in diameter. The specific surface area $\left(150 \mathrm{~m}^{2}\right.$ $\mathrm{g}^{-1}$ ) mainly originates from interparticle porosity in the mesoporous range (pore size 5$15 \mathrm{~nm}$ ). Electron micrographs of NP and CP are provided in Supplementary Material.

\subsection{Adsorption studies}

Adsorption kinetics was followed in batch experiments conducted at $25^{\circ} \mathrm{C}$ by adding $200 \mathrm{mg}$ of sorbent to $100 \mathrm{~mL}$ of an aqueous solution containing $20 \mathrm{mg} \mathrm{L}^{-1}$ of antibiotic. The $\mathrm{pH}$ of the mixture was adjusted to 5.6 and the suspension kept under mechanical 
stirring over 3 hours. Sorption isotherm studies were conducted in similar conditions using antibiotics concentrations in the $5-130 \mathrm{mg} \mathrm{L}^{-1}$ range. At selected time interval, the suspensions were sampled through direct filtration using $0.45 \mu \mathrm{m}$ membrane filter. The antibiotic concentration in supernatant was monitored using a UV-visible spectrophotometer (Perking Elmer Lamda 35) working at $\lambda=230 \mathrm{~nm}, 244 \mathrm{~nm}, 273 \mathrm{~nm}$, $295 \mathrm{~nm}$ for AMO, SUL, CIP and OFL, respectively. To study the effect of $\mathrm{pH}$ on antibiotics sorption, addition of $\mathrm{HNO}_{3}$ or $\mathrm{NaOH}$ to the antibiotic solutions was performed. UV-visible spectra of antibiotics were recorded at all $\mathrm{pH}$ values in order to detect any variations in optical density at the selected wavelength and correct the concentration values accordingly

For the detection of low levels of antibiotics and for the study of multiple antibiotics adsorption, high performance liquid chromatography (HPLC) was used. The conditions were: (i) CIP : Agilient-Zorbax C18 SB (250 x $4.6 \mathrm{~mm}) 5 \mu \mathrm{m}$; column temperature : $40{ }^{\circ} \mathrm{C}$, mobile phase : $\mathrm{H}_{3} \mathrm{PO}_{4}$-trimethylamine (pH 3):acetonitrile (87 :13), flow : 1.5 mL.min ${ }^{-1}$; injected volume : $50 \mu \mathrm{L}$; (ii) OFL : GL Sciences Inc Inertsil C18 $(250$ x 4.6 mm) $5 \mu \mathrm{m}$; column temperature : $45^{\circ} \mathrm{C}$; mobile phase : $\mathrm{CH}_{3} \mathrm{COONH}_{4}-\mathrm{NaClO}_{4}-\mathrm{H}_{3} \mathrm{PO}_{4}$ (pH 2.2) :acetonitrile (85:15); flow $2 \mathrm{~mL} \cdot \mathrm{min}^{-1}$; injected volume : $100 \mu \mathrm{L}$; (iii) AMO : Water Symmetry C18 (250 x $4.6 \mathrm{~mm}) 5 \mu \mathrm{m}$, mobile phase : $\mathrm{NaH}_{2} \mathrm{PO}_{4}(\mathrm{pH} 4.4)$ : $\mathrm{H}_{3} \mathrm{PO}_{4} /$ methanol (98:2), flow : $1 \mathrm{~mL} \cdot \mathrm{min}^{-1}$; injected volume : $100 \mu \mathrm{L}$; (iv) SUL : Water XTerra MS C18 (250 x $4.6 \mathrm{~mm}) 5 \mu \mathrm{m}$; column temperature : $30{ }^{\circ} \mathrm{C}$; mobile phase : $\mathrm{KH}_{2} \mathrm{PO}_{4}(\mathrm{pH} 5.3): \mathrm{KOH} / \mathrm{methanol}(65: 35)$, flow : $1 \mathrm{~mL} \cdot \mathrm{min}^{-1}$; injected volume : $50 \mu \mathrm{L}$

The amount of sorbed antibiotic was calculated by using Eq. (1)

$$
q_{t}=\frac{C_{0}-C_{e}}{m} V
$$


where $q_{t}$ is the amount of adsorbed antibiotic at time $t\left(\mathrm{mg} \mathrm{g}^{-1}\right), C_{0}$ and $C(t)$ are the antibiotic concentration in solution at $\mathrm{t}=0$ and $\mathrm{t}=t\left(\mathrm{mg} \mathrm{L}^{-1}\right), V$ is the volume $(\mathrm{L})$ of the antibiotic solution and $m$ is the weight $(\mathrm{g})$ of the sorbent. All experiments were carried out in triplicate. The mean values are reported and the error range was always $<5 \%$.

In order to determine the kinetics parameters of the sorption reactions, Lagergren pseudo-first (Srihari et al., 2008) and pseudo-second order (Ho, 2006) models have been applied to experimental data. The first model allows the determination of $q_{e, 1}$ the calculated amount of adsorbed antibiotic at equilibrium $\left(\mathrm{mg} \mathrm{g}^{-1}\right)$ and $k_{I}$ the first order kinetic constant $\left(\mathrm{min}^{-1}\right)$. The second model provides $q_{e, 2}$ the calculated amount of adsorbed antibiotic at equilibrium $\left(\mathrm{mg} \mathrm{g}^{-1}\right)$ and $k_{2}$ the second order kinetic constant ( $\mathrm{g}$ $\left.\mathrm{mg}^{-1} \min ^{-1}\right)$

Sorption isotherms were analyzed using the Langmuir and Freundlich models (Mittal et al., 2007). The first model allows the calculation of $q_{e, \max }$ the maximum amount of adsorbed antibiotic at equilibrium $\left(\mathrm{mg} \mathrm{g}^{-1}\right)$, and $\beta$ is the Langmuir constant $\left(\mathrm{L}^{\mathrm{m}} \mathrm{mg}^{-1}\right)$ related to the adsorption energy. The second model leads to the determination of $K_{f}$ the Freundlich constant correlated to the maximum adsorption capacity and $n$ the adsorption intensity, respectively.

Analyses of the calcium content of the solutions before and after antibiotic sorption was performed using inductively coupled plasma (ICP) emission spectroscopy (ICPS-7500, Shimadzu, Japan)

\section{Results and discussion}

Kinetics study of the sorption process was first conducted at low antibiotic concentration $\left(20 \mathrm{mg} \mathrm{g}^{-1}\right)$. SUL, CIP and OFL show a similar, fast rate of sorption over the first 30 min of contact before an equilibrium is reached (Fig. 2). In contrast, the 
immobilization of AMO is significantly slower, with equilibrium being observed after ca. 3 h.
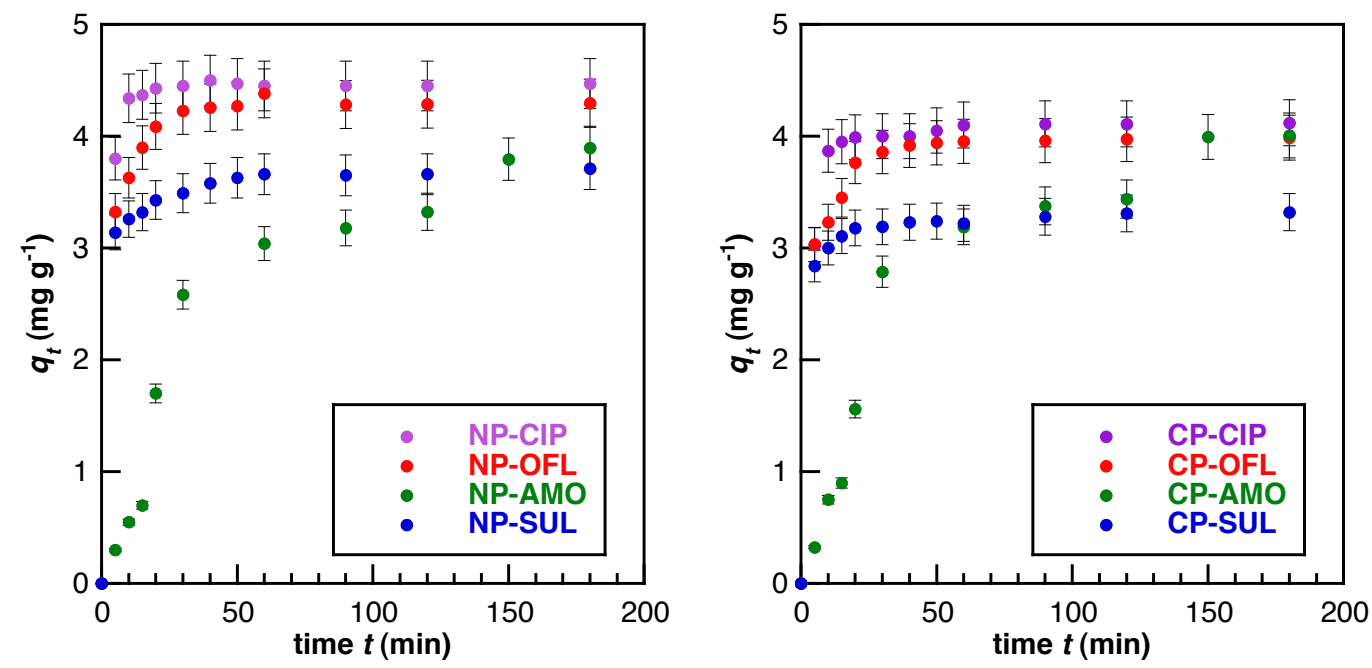

Fig.2 Evolution of the amount of sorbed antibiotic $\left(q_{t}\right)$ with contact time $t$ on the natural phosphate (NP) and converted (CP) phosphate powder

The Langergren's pseudo second-order kinetic model $\left(k_{2}\right.$ and $\left.q_{e, 2}\right)$ was found welladapted to reproduce the kinetics data for the first three antibiotics on both NP and CP (Table 1$)$. The kinetics constants vary in the order $k_{2}(\mathrm{CIP})>k_{2}(\mathrm{OFL}) \approx k_{2}(\mathrm{SUL})$ for NP and $k_{2}(\mathrm{CIP}) \approx k_{2}(\mathrm{SUL})>k_{2}(\mathrm{OFL})$ for CP. In contrast, the pseudo first-order model was found more adapted to describe the AMO sorption kinetics. However, lower reliability of the fitting procedure was observed for CP data $\left(R^{2}=0.981\right)$ compared NP $\left(R^{2}=\right.$ $0.989)$.

Table 1 Kinetic rate constants $(k)$ and adsorption capacities $(q)$ as obtained for different models for antibiotic sorption by the natural and converted phosphate powder. $R^{2}$ indicate the correlation coefficients for the linear fits.

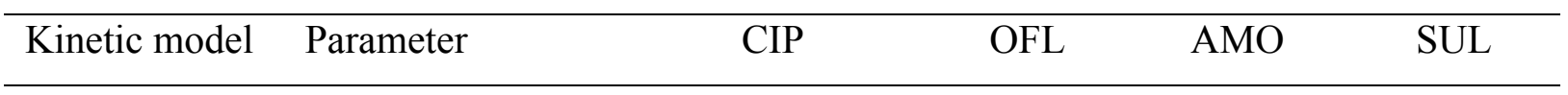

\section{Natural phosphate}




\begin{tabular}{|c|c|c|c|c|c|}
\hline & $k_{l}\left(\min ^{-1}\right)$ & 0.17 & 0.06 & 0.02 & 0.05 \\
\hline \multirow{3}{*}{$\begin{array}{l}\text { Pseudo } \\
\text { order }\end{array}$} & $q_{e, 1}\left(\mathrm{mgg}^{-1}\right)$ & 1.7 & 1.1 & 3.8 & 1.2 \\
\hline & $R^{2}$ & 0.922 & 0.909 & 0.989 & 0.922 \\
\hline & $k_{2}\left(\min ^{-1}\right)$ & 0.47 & 0.26 & $<0.01$ & 0.20 \\
\hline \multirow{4}{*}{$\begin{array}{l}\text { Pseudo second } \\
\text { order }\end{array}$} & $q_{e, 2}\left(\mathrm{gmg}^{-1} \min ^{-1}\right)$ & 4.4 & 4.3 & 5.6 & 3.7 \\
\hline & $R^{2}$ & 0.999 & 0.999 & 0.944 & 0.999 \\
\hline & \multicolumn{4}{|c|}{ Converted phosphate } & \\
\hline & $k_{l}\left(\min ^{-1}\right)$ & 0.06 & 0.07 & 0.02 & 0.06 \\
\hline \multirow{3}{*}{$\begin{array}{l}\text { Pseudo } \\
\text { order }\end{array}$} & $q_{e, 1}\left(\mathrm{mgg}^{-1}\right)$ & 2.5 & 2.5 & 3.6 & $\mathrm{~N} / \mathrm{A}$ \\
\hline & $R^{2}$ & 0.876 & 0.961 & 0.981 & 0.838 \\
\hline & $k_{2}\left(\min ^{-1}\right)$ & 0.27 & 0.18 & $<0.01$ & 0.29 \\
\hline \multirow{2}{*}{$\begin{array}{l}\text { Pseudo second } \\
\text { order }\end{array}$} & $q_{e, 2}\left(\mathrm{gmg}^{-1} \mathrm{~min}^{-1}\right)$ & 4.2 & 4.0 & 5.0 & 3.3 \\
\hline & $R^{2}$ & 0.999 & 0.999 & 0.952 & 0.999 \\
\hline
\end{tabular}

The retention capacity of natural and converted phosphate powders was then studied by performing sorption isotherms for initial antibiotic concentrations ranging from $5 \mathrm{mg}$ $\mathrm{L}^{-1}$ to $130 \mathrm{mg} \mathrm{L}^{-1}$ over $3 \mathrm{~h}$. In all cases, sorbent saturation was reached and experimental maximum capacities $q_{\max }$ were found between $19 \mathrm{mg} \mathrm{g}^{-1}$ and $24 \mathrm{mg} \mathrm{g}^{-1}$ (Fig. 3). On both sorbents, the highest capacities were found for OFL molecules. Variations between the $\mathrm{NP}$ and CP were within the error range $\left(5 \%\right.$, i.e. $\left.\pm 1 \mathrm{mg} \mathrm{g}^{-1}\right)$ of the measurements.
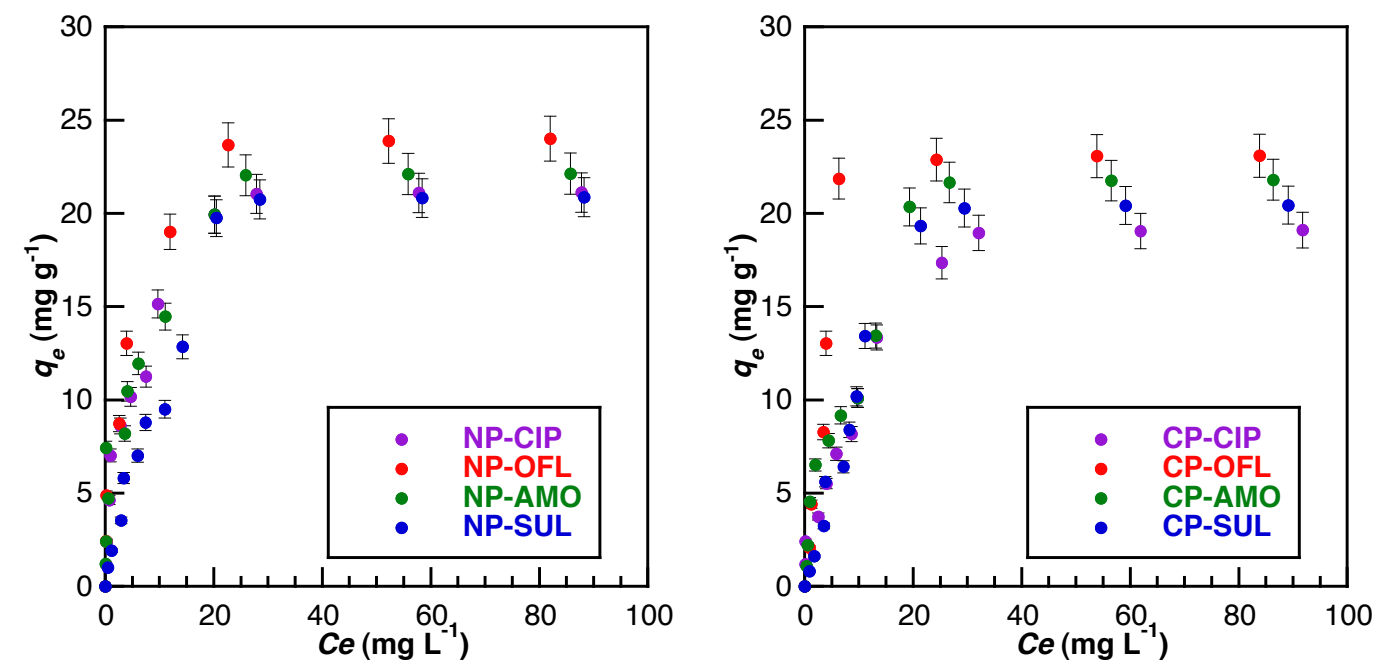

Fig. 3 Variation of sorbed antibiotic content $\left(q_{e}\right)$ with antibiotic concentration at 
equilibrium on the natural (NP) and converted phosphate $(\mathrm{CP})$ powders

A correct fitting of the experimental data with Langmuir equation $\left(R^{2}>0.99\right)$ was obtained for OFL, CIP and AMO (Table 2). Calculated $q_{e, \text { max }}$ values were in good agreement with experimental values. The largest $\beta$ value was obtained for OFL while this parameter had a similar value for CIP and AMO. In the case of SUL, the Freundlich model was found more adapted to fit the experimental data. Noticeably, a systematic decrease in $\beta$ and $R^{2}$ values for OFL, CIP and AMO was obtained for CP compared to NP. The same trend was evidenced for $K_{f}$ and $R^{2}$ values calculated from modeling of SUL sorption data, while $1 / n$ increased.

Table 2 Langmuir and Freundlich constants for antibiotics sorption on the natural and converted phosphate powder

\begin{tabular}{|c|c|c|c|c|c|}
\hline & & CIP & OFL & AMO & SUL \\
\hline \multicolumn{6}{|c|}{ Natural phosphate } \\
\hline Experimental & $q_{\max }\left(\mathrm{mg} \mathrm{g}^{-1}\right)$ & 21 & 24 & 22 & 21 \\
\hline \multirow[t]{3}{*}{ Langmuir } & $q_{e, \max }\left(\mathrm{mg} \mathrm{g}^{-1}\right)$ & 22.2 & 24.4 & 23.3 & 25.0 \\
\hline & $\beta\left(\mathrm{L} \mathrm{mg}^{-1}\right)$ & 0.32 & 0.73 & 0.39 & 0.08 \\
\hline & $R^{2}$ & 0.997 & 0.995 & 0.994 & 0.982 \\
\hline \multirow[t]{3}{*}{ Freundlich } & $K_{f}\left(\mathrm{~L} \mathrm{~g}^{-1}\right)$ & 4.89 & 7.08 & 5.01 & 1.78 \\
\hline & $1 / n$ & 0.49 & 0.44 & 0.48 & 0.75 \\
\hline & $R^{2}$ & 0.978 & 0.958 & 0.975 & 0.993 \\
\hline \multicolumn{6}{|c|}{ Converted phosphate } \\
\hline Experimental & $q_{\max }\left(\mathrm{mg} \mathrm{g}^{-1}\right)$ & 19 & 23 & 22 & 20 \\
\hline \multirow[t]{3}{*}{ Langmuir } & $q_{e, \max }\left(\mathrm{mg} \mathrm{g}^{-1}\right)$ & 20.8 & 24.4 & 23.8 & 25.6 \\
\hline & $\beta\left(\mathrm{L} \mathrm{mg}^{-1}\right)$ & 0.14 & 0.25 & 0.16 & 0.06 \\
\hline & $R^{2}$ & 0.990 & 0.994 & 0.991 & 0.956 \\
\hline \multirow[t]{2}{*}{ Freundlich } & $K_{f}\left(\mathrm{~L} \mathrm{~g}^{-1}\right)$ & 3.24 & 3.47 & 3.47 & 1.35 \\
\hline & $1 / n$ & 0.59 & 0.72 & 0.45 & 0.90 \\
\hline
\end{tabular}




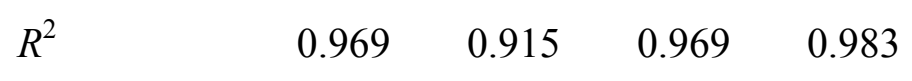

Understanding these results requires to examine and compare the chemical properties of the four antibiotics along three parameters that can influence their sorption behaviours, i.e. dimensions, charge and hydrophilicity/hydrophobicity (Fig. 1). The first parameter can be assessed considering the molecular weight $(M W)$ of the molecules. In this context, CIP, OFL and AMO have close $M W \mathrm{~s}$ whereas SUL is significantly smaller. Noticeably, when calculating sorption capacities per mole of antibiotic, one obtain for NP sorption isotherms, $q_{e, \max }=0.08 \mathrm{mmol} \mathrm{g}^{-1}$ for SUL and $q_{e, \max }=0.06 \mathrm{mmol} \mathrm{g}^{-1}$ for other antibiotics. This is in agreement with the fact that a given sorbent surface can, in principle, accommodate more small molecules than large ones.

Coming to the molecular charge, the $p K_{a}$ values of the various ionizable groups allow the determination of the main forms of each antibiotic at $\mathrm{pH} 5.6$ (Fig. 4). For CIP, the amine group of the piperazinyl ring is positively charged whereas the carboxyl group is mainly in its protonated form so that this antibiotic is mainly in a cationic form. OFL has close $p K_{a}$ values and is therefore also cationic. In contrast, the acidity of the $\mathrm{COOH}$ group of $\mathrm{AMO}$ is much higher so that it is deprotonated at $\mathrm{pH}$ 5.6. Therefore, the prevalent form of AMO is zwitterionic. Finally, SUL has two rather acidic amine groups with $p K_{a}$ of 1.6 and 5.7. Therefore, at $\mathrm{pH} 5.6$, neutral and anionic forms are coexisting in similar amounts. In parallel, the point of zero charge of hydroxyapatite is in the $\mathrm{pH}$ 7-8 range (Bell et al., 1973), mainly resulting from the balance between $\mathrm{POH} / \mathrm{PO}^{-}$and $\mathrm{Ca}^{2+}$ groups. At $\mathrm{pH} 5.6$, the surface is therefore slightly positive. Therefore one should expect a favored adsorption of SUL compared to the three other antibiotics. In contrast, OFL and CIP should be less efficiently retained than AMO. In principle, the strength of interaction between the antibiotics and the surface can be 
estimated from $\beta$ Langmuir parameter and $1 / n$ Freundlich parameter. Unfortunately, the SUL sorption process could not be suitably fitted using the Langmuir model so that comparison with the three other antibiotics is difficult. Nevertheless, it must be noted that calculated $1 / n$ values are relatively large, indicating a strong interaction between SUL and the sorbent phase. As far as the other antibiotics are concerned, one should notice that OFL sorption is systematically associated with a larger $\beta$ value than CIP and AMO. Therefore another parameter must be taken into account.

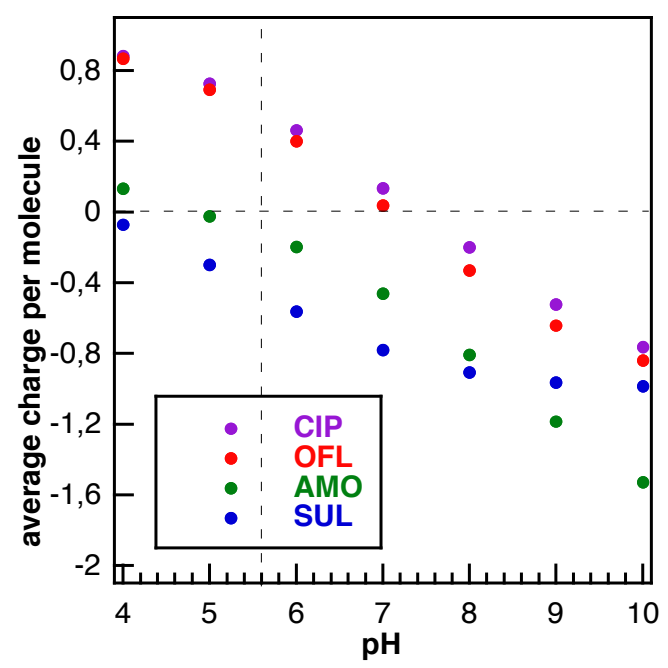

Fig. 4 Calculated average charge per molecule for the four antibiotics

The $X \log P 3$ values provide an indication of the hydrophilic/hydrophobic balance of the molecules (Cheng et al., 2007). On this basis, the hydrophilic character of the considered antibiotics follows the order AMO $>$ CIP $>$ OFL $>$ SUL. However partition coefficients are calculated using the unionized form of the molecules, being therefore fully relevant for AMO, partially adapted for SUL and must be taken with care for CIP and OFL. A better insight can be obtained by examining the 3D molecular structure of these different antibiotics (Fig. 5). In the SUL structure, the planes of two aromatic rings form a $c a .130^{\circ}$ angle. The terminal primary amine is easily accessible whereas the central secondary amine is buried between the aromatic rings. This explains the 
strong hydrophobic character of this molecule. It also suggests that SUL adsorbs on the apatite surface via the terminal amine group, probably adopting a edge-on conformation due to the repulsion of the hydrophilic mineral surface and the hydrophobic rings. For $\mathrm{AMO}$, only one aromatic ring is present. Several hydrophilic moieties, i.e. terminal phenol and carboxylate groups as well as a central primary amine are easily accessible, providing a significant hydrophilic character to the molecule. This structure suggests the possibility for AMO to adopt a flat conformation of the surface via carboxylate and amine moieties, keeping the hydrophobic region away from the hydrophilic mineral surface. The CIP and OFL molecules are intermediate cases since they exhibit a tworings aromatic structure accounting for their hydrophobicity but their ionizable hydrophilic moieties (amine and carboxylate) are located at the two opposite ends of the molecules and therefore remain accessible. In both cases, the piperazinyl ring main axis forms a ca. $150^{\circ}$ angle with the aromatic rings. The main difference between these two structures is the lowest accessibility of the amine end group of these piperazinyl rings, with the secondary amine moiety of CIP being more hydrophilic that the tertiary amine of OFL. Considering their conformation on the surface, an edge-on conformation similar to AMO with terminal groups interacting with the surface can be suggested. Since the carboxyl groups of CIP and OFL are neutral at pH 5.6, the most plausible moieties for interaction with the apatite surface are the terminal amine groups that are positively charged at this $\mathrm{pH}$.

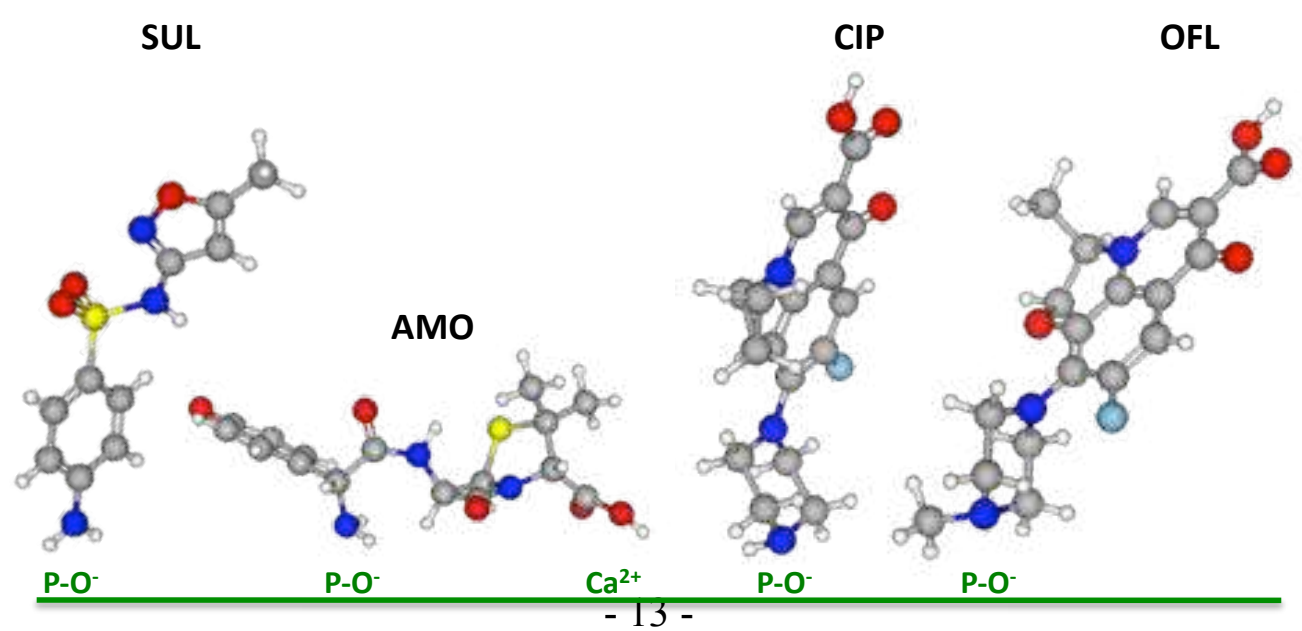


Fig. 5 Molecular structure of the antibiotics and their proposed mode of adsorption on the apatite surface. (color code: white: H; grey: C; blue: N; yellow: S; green represent the apatite surface)

In this context, it is interesting to note that AMO is the only molecule whose sorption kinetics was suitably fitted by a pseudo-first order model. This means that AMO molecules are adsorbed individually on the surface, in agreement with its hydrophilic character. In contrast, aromatic hydrophobic molecules have a tendency to interact one with another in water, so that they would tend to get adsorbed as dimers (or larger aggregates). This explains why higher-order models are required to fit the kinetics data of the three other antibiotics. In parallel, the sorption isotherms of AMO, CIP and OFL are well-fitted by a Langmuir equation corresponding to a single layer deposition. This can be explained considering that for these three molecules, multi-layer stacking via intermolecular interactions of aromatic rings are sterically limited due to the presence of non-aromatic cycles pointing out of their plane. In contrast, for SUL, possible molecular stacking via $\pi-\pi$ interactions are possible, that would explain the better suitability of the Freundlich model, that applies to heterogeneous, sometimes multi-layered sorption, to fit the experimental data.

The comparison between the two sorbents reveals that the conversion process does not induce significant modification of the maximum capacities. This can be surprising considering that the specific surface area of the powder after conversion increases from $20 \mathrm{~m}^{2} \mathrm{~g}^{-1}$ to $150 \mathrm{~m}^{2} \mathrm{~g}^{-1}$. A similar observation was reported for pyridine adsorption on similar materials (Bouyarmane et al., 2010). It was attributed to the fact that adsorption 
of this molecule destabilizes the surface-coated CP nanoparticles, leading to their aggregation and therefore loss of available surface for further sorption. Another explanation lies in the hydrophobic character of francolite compared to hydroxyapatite (Lu et al., 1997) that should favor the surface interactions of NP with the antibiotics compared to CP.

To clarify the process of sorption, the effect of $\mathrm{pH}$ on antibiotics sorption was studied in the 4-10 range (Fig. 6) and analyzed using the calculated pH-charge curves (Fig. 4). As a common trend, the sorption capacity slightly increases with increasing $\mathrm{pH}$ for all antibiotics and for the two sorbents. For NP, these values increased of ca. 15-20\% for CIP and OFL and 20-25\% for SUL and AMO. For CP, similar values were obtained for CIP and OFL whereas sorption capacity increased by $25-30 \%$ for SUL and AMO. As mentioned earlier, the isoelectric point of hydroxyapatite is ca. 7-8, resulting from the contribution of $\mathrm{Ca}^{2+}, \mathrm{OH}^{-}$, and phosphates groups. CIP and OFL are mainly in a positively charged form at $\mathrm{pH} 4$. With increasing $\mathrm{pH}$, deprotonation of the carboxylic acid function first occurs leading to zwitterionic species until the piperazinyl rings become neutral, resulting in a major negative form above 9. SUL is mainly neutral at $\mathrm{pH} 4$ and the negative form then become prevalent at higher $\mathrm{pH}$ due to deprotonation on the central amine group. Accordingly AMO is zwitterionic at $\mathrm{pH} 4$ due to the coexistence of carboxylates and ammonium groups and the negative form becomes more abundant with increasing $\mathrm{pH}$ as the latter groups become neutral. At higher $\mathrm{pH}$, the deprotonated phenol function further increase the negative charge of the molecule. Thus from an general electrostatic point of view, an increase in antibiotic sorption between $\mathrm{pH} 4$ and $\mathrm{pH}$ 7-8 can be understood for SUL and AMO considering that their negative form is becoming more abundant while hydroxyapatite remains positivelycharged, allowing for electrostatic attractive interactions to occur. For CIP and OFL, it 
can be suggested that the decreasing abundance of positively-charged molecular forms with increasing $\mathrm{pH}$ parallels the decreasing positive charge of the hydroxyapatite surface, therefore lowering electrostatic repulsive interactions. Note that attractive interactions between positively-charged molecules and deprotonated phosphates are also possible. Nevertheless, the more limited increase in sorption capacity observed for CIP and OFL compared to AMO and SUL suggest that the latter interactions are less effective than the former. Unfortunately, the low amount of sorbed antibiotics did not allow for further analysis of the sorption process by Infra-red spectroscopy (see Supplementary Material).
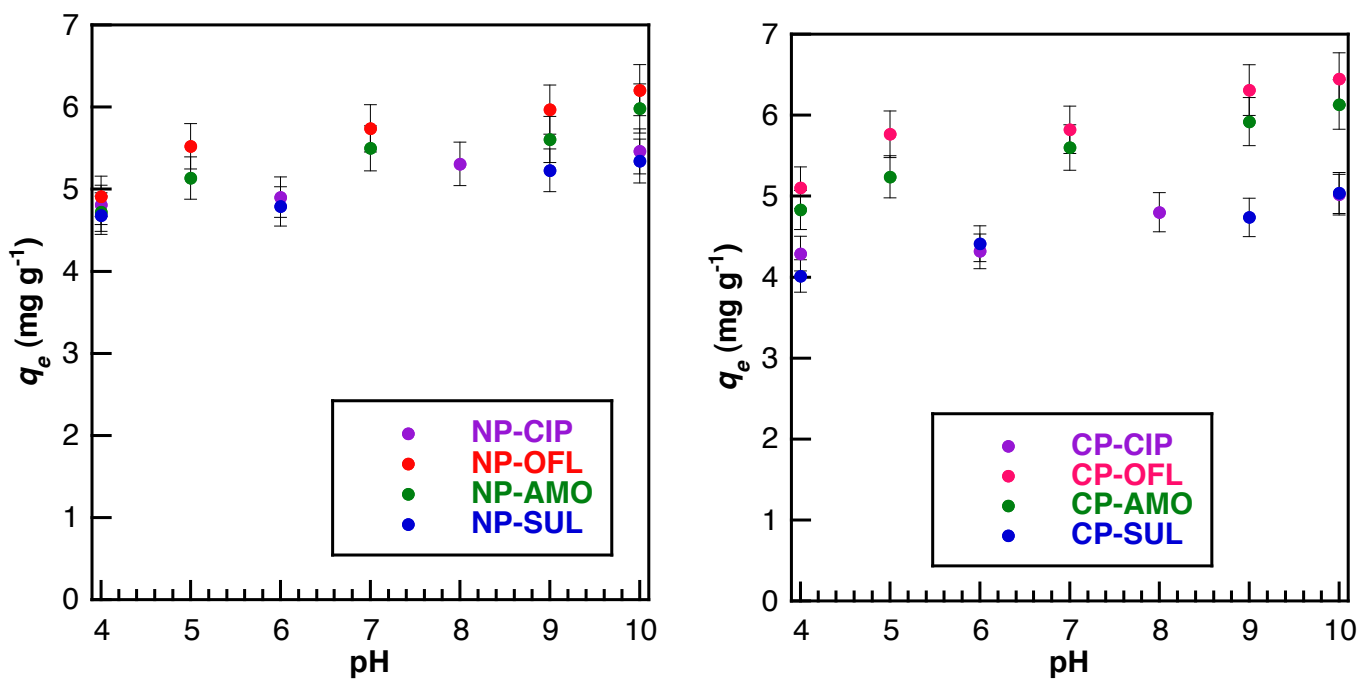

Fig. 6 Variation of sorbed antibiotics $\left(q_{e}\right)$ with $\mathrm{pH}$ on the natural (NP) and converted phosphate $(\mathrm{CP})$ powders

Then, the continuous increase in sorption capacity above $\mathrm{pH} 8$ is more difficult to explain, as both antibiotics and hydroxyapatite surface become more negative as $\mathrm{pH}$ increases. The most plausible explanation is that despite the overall negative charge of hydroxyapatite, local interactions between carboxylate groups and calcium surface ions are possible. In addition, a previous report on pyridine sorption of hydroxyapatite 
showed a similar increase in sorption capacity above the point of zero-charge of the sorbing phase (Bouyarmane et al., 2010). At this time, it was suggested that neutral amines could interact with $\mathrm{Ca}^{2+}$ ions present on the surface. As a matter of fact, all four antibiotics bear amine groups that can be involved in such attractive interactions. Importantly, the $\mathrm{Ca}^{2+}$ content of the supernatant of the powders was determined before and after antibiotic sorption. In all cases, this amount was lower than $0.1 \mathrm{mg} \cdot \mathrm{mL}^{-1}$, a value that must be compared with the initial 2 g.mL $\mathrm{m}^{-1}$ calcium phosphate (i.e. ca. 1 g. $\mathrm{mL}^{-1} \mathrm{Ca}$ ) content. This allows to exclude any significant cation exchange reaction. It is also worth mentioning that for SUL and AMO, the progressive formation of more negative species with increase in $\mathrm{pH}$ increase also correlate with a decrease in their hydrophobic character, which can favor their adsorption. This can explain why these antibiotics show a higher increase in sorption in basic media on the hydrophilic CP compared to the more hydrophobic NP.

In a step further, the adsorption of a mixture of the four antibiotics at a similar concentration $\left(20 \mathrm{mg} . \mathrm{L}^{-1}\right)$ was studied. The amount of sorbed molecules at equilibrium $q_{e}$ are shown in Fig.7 and compared with values obtained for antibiotics alone at the same concentration. Each antibiotic was adsorbed at a $2.2-3.2 \mathrm{mg} \cdot \mathrm{g}^{-1}$ content so that the total amount of adsorbed antibiotics from the mixture was $c a .10 \mathrm{mg} . \mathrm{g}-1$. As a comparison, these value varied between $4.5 \mathrm{mg} \cdot \mathrm{g}^{-1}$ and $9 \mathrm{mg} \cdot \mathrm{g}^{-1}$ for individual molecules at an initial $20 \mathrm{mg} \cdot \mathrm{mL}^{-1}$ concentration and reached ca. $20 \mathrm{mg} \cdot \mathrm{g}^{-1}$ at an initial $80 \mathrm{mg} \cdot \mathrm{mL}^{-1}$ content. Therefore, the overall sorption ability of the powders was halved when antibiotic mixtures were present. Such a decrease could be expected considering that the sorption process appears to be strongly dependent on intermolecular interactions that can be perturbed by the presence of other components. In this context, it is interesting to notice that whereas the amount of sorbed CIP was larger than that of OFL 
in simple solutions, this trend is reversed in mixtures, suggesting that despite their close structural and chemical features, some subtle variations in conformation and/or functional group accessibility can significantly impact on their behavior.

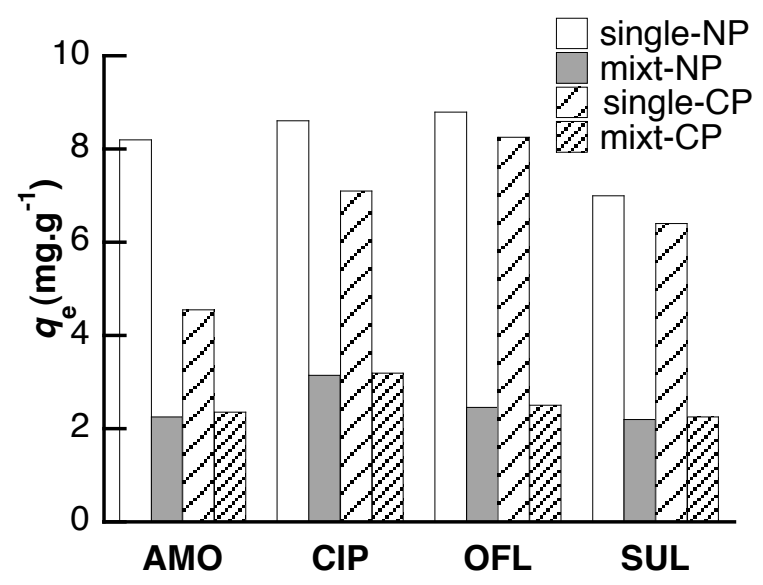

Fig. 7 Variation of sorbed antibiotics $\left(q_{e}\right)$ as single components or from mixtures on natural (NP) and converted phosphate (CP) powders (antibiotic concentration : 20 mg. $\mathrm{mL}^{-1}$ each)

Finally, it is important to compare the sorption properties of these materials with those reported in the literature (Homem and Santos, 2011). For instance, for SUL, $K_{f}$ values (in $\mathrm{L} \mathrm{kg}^{-1}$ ) are ca. 1-2 for sediments (Hou et al., 2010) and 10 for clays (Gao and Pedersen, 2005), therefore much higher than here-reported values. Our data suggest that this poor affinity is due to the low surface charge of francolite and hydroxyapatite in the 5-7 $\mathrm{pH}$ range, preventing strong attractive electrostatic interactions with here-studied antibiotics. In these conditions, it is expected that calcium phosphates, being natural or synthetic, do not significantly contribute to the immobilization of here-studied 
antibiotics in soils, in agreement with the literature (Wegst-Ulrich et al., 2014).

However, we evidenced the importance of the hydrophobic character of these molecules on their sorption, an observation that can apply to a large range of bioactive agents exhibiting lipophilic properties. These data can contribute to a better understanding of the fate of antibiotics in soils, a field where the influence of the hydrophobic character of the drug is so far poorly understood. In this context, francolite rocks appear as particularly interesting material for further studies, as a major form of natural calcium phosphates.

\section{Acknowledgments}

The authors thank the CNRS for funding this research through the APATENV project of the PICS program. T.C and S. M. are very thankful to M. Selmane and F. Tielens (LCMCP) for their assistance in the determination of molecular structures.

Appendix A. Supplementary Material

Electron microscopy images of the natural and converted phosphate powders. Selected FTIR spectra of the powders after antibiotic sorption.

\section{References}

A. Bahdod, S. El Asri, A. Saoiabi, T. Coradin, A. Laghzizil, Adsorption of phenol from an aqueous solution by selected apatite adsorbents: Kinetic process and impact of the surface properties. Water Res. 43 (2009) 313-318.

L.C. Bell, A.M. Posner, J.P. Quirk, The point of zero charge of hydroxyapatite and fluorapatite in aqueous solutions. J. Colloid Interface Sci. 42 (1973) 250-261.

H. Bouyarmane, S. El Asri, A. Rami, C. Roux, M.A. Mahly, A. Saoiabi, T. Coradin, A. 
Laghzizil, Pyridine and phenol removal using natural and synthetic apatites as low cost sorbents: Influence of porosity and surface interactions. J. Hazard. Mater. 181 (2010) $736-741$

A.B.A Boxall, P. Blackwell, R. Cavallo, P. Kay, J. Tolls, The sorption and transport of a sulphonamide antibiotic in soil systems. Toxicol. Lett. 131 (2002) 19-28.

H. Chen, B. Gao, H. Li, L.Q. Ma, Effects of $\mathrm{pH}$ and ionic strength on sulfamethoxazole and ciprofloxacin transport in saturated porous media. J. Contamin. Hydrol. 126 (2011) 29-36.

E.E. Chen, K.C. Jones, G.G Ying, H. Zhang, Desorption kinetics of Sulfonamide and Trimethoprim antibiotics in soils assessed with diffusive gradients in thin-films. Environ. Sci. Technol. 48 (2014) 5530-5536

T. Cheng, Y. Zhao, X. Li, F. Lin, X. Yong, X. Zhang, Y. Li, R. Wang, L. Lai, Computation of octanol-water partition coefficients by guiding and additive model with knowledge. J. Chem. Inf. Model. 47 (2007) 2140-2148.

M.S. Díaz-Cruz, Environmental behavior and analysis of veterinary and human antibiotics in soils, sediments and sludge. Trends Anal. Chem. 22 (2003) 340-351.

S. El Asri, A. Laghzizil, A. Alaoui, A. Saoiabi, R. M'Hamdi, K. El Abbassi, A. Hakam, Structure and thermal behaviours of Moroccan phosphate rock. J. Therm. Anal. Calorim. 95 (2009a) 11-15.

S. El Asri, A. Laghzizil, A. Saoiabi, A. Alaoui, K. El Abbassi, R. M’Hamdi, T. Coradin, A novel process for the fabrication of nanoporous apatites from Moroccan phosphate rock. Colloids Surf. A 35 (2009b) 73-78.

J. Gao, J.A. Pedersen, Adsorption of sulphonamide antimicrobial agents to clay minerals. Environ. Sci. Technol. 39 (2005) 9509-9516. 
C. Gu, K.G. Karthikeyan, Sorption of antimicrobial ciprofloxacin to aluminium and iron hydrous oxides. Environ. Sci. Technol. 39 (2005) 9166-9173.

Y.S. Ho, Review of second-order models for adsorption systems. J. Hazard Mater. 136 (2006) 681-689.

V. Homem, L. Santos, Degradation and removal methods of antibiotics from aqueous matrices - a review. J. Environ Management 92 (2011) 2304-2347.

J. Hou, B. Pan, X. Niu, J. Chen, B. Xing. Sulfamethoxazole sorption by sediment fractions in comparison to pyrene and bisphenol A. Environ. Pollut. 158 (2010) 28262832.

K. Kumar, S.C Gupta, Y. Chander, A.K. Singh, Antibiotic use in agriculture and its impact on the terrestrial environment. Adv. Agron. 87 (2005) 1-54.

K. Kümmerer, Antibiotics in the aquatic environment -a review-Part I. Chemosphere 75 (2009a) 417-434.

K. Kummerer Antibiotics in the aquatic environment-a review-Part II. Chemosphere 75 (2009b) 435-441.

Y.C. Lin, T.H. Yu, C.F. Lin, Pharmaceutical contamination in residential, industrial and agricultural waste streams: risk to aqueous environments in Taiwan. Chemosphere 74 (2008) 131-141.

K. Lin, Y. Pan, R. Chen, X. Cheng, X. Xu, Study of the adsorption of phenol from aqueous solution onto apatite nanopowders. J. Hazard. Mater. 161 (2009) 231-240

Y. Lu, J. Drelich, J.D. Miller, Wetting of francolite and quartz and its significance in the flotation of phosphate rock. Minerals Engin. 10 (1997) 1219-1231

Y. Mamindy-Pajany, C. Hurel, F. Geret, M. Roméo, N. Marmier, Comparison of mineral-based amendments for ex-situ stabilization of trace elements (As, Cd, Cu, Mo, 
$\mathrm{Ni}, \mathrm{Zn}$ ) in marine dredged sediments: A pilot-scale experiment. J. Hazard. Mater. 252253 (2013) 213-219

P. Miretzky, A. Fernandes-Cirelli, Phosphates for $\mathrm{Pb}$ immobilization in soils : a review. Environ. Chem. Lett. 6 (2008) 121-133.

A. Mittal, L. Kurup, J. Mittal, Freundlich and Langmuir adsorption isotherms and kinetics for the removal of Tatrazine from aqueous solutions using hen feathers. J. Hazard. Mater. 146 (2007) 243-248.

G. Moulin, P. Cavalie, I. Pellanne, A. Chevance, A. Laval, Y. Millemann, P. Colin, C. Chauvin, A comparison of antimicrobial usage in human and veterinary medicine in France from 1999 to 2005. J. Antimicrob. Chemother. 62 (2008) 617-625.

A. Nzihou, P. Sharrock, Role of phosphate in the remediation and reuse of heavy metal polluted wastes and sites. Waste Biomass Valor. 1 (2010) 163-174.

P.A. O’Day, D. Vlassopoulos, Mineral-based amendments for remediation. Elements 6 (2010) 375-381.

V. Srihari, A. Das, The kinetics and thermodynamic studies of phenol-sorption on three agro-based carbons. Desalination 225 (2008) 220-234.

S. Thiele-Bruhn, Pharmaceutical antibiotic compounds in soils-a review. J. Plant Nutr. Soil Sci. 166 (2003) 145-67.

S.R. Wegst-Ulrich, D.A.G. Navarro, L. Zimmerman, Assessing antibiotic sorption in soil: a literature review and new case studies on sulfonamides and macrolides. Chem. Central J. 8 (2014) 5 